\title{
PHF20L1 antagonizes SOX2 proteolysis triggered by the MLL1/WDR5 complexes
}

\author{
Qianqian Wang ${ }^{1} \cdot$ Min $\mathrm{Yu}^{1} \cdot$ Yue $\mathrm{Ma}^{1} \cdot$ Xiaoming Zhang ${ }^{1} \cdot$ Hui Zhang ${ }^{2} \cdot$ Shuiming $\mathrm{Li}^{3} \cdot$ Rongfeng $\mathrm{Lan}^{4} \cdot$ Fei Lu $\mathbb{( i )}^{1}$
}

Received: 14 August 2017 / Revised: 25 May 2018 / Accepted: 13 June 2018 / Published online: 8 August 2018

(c) United States \& Canadian Academy of Pathology 2018

\begin{abstract}
Transcriptional factor SOX2 regulates stem cell pluripotency, cell differentiation and tumorigenesis. As a key factor, the expression of SOX2 is tightly regulated at transcriptional and post-translational levels. However, the underlying mechanism of SOX2 protein stability remains to be elucidated. Here we show that the histone-lysine $N$-methyltransferase MLL1/WDR5 complexes physically interact with SOX2 and evoke SOX2 proteolysis, possibly through methylation on a potential site lysine 42 (K42). Small interfering RNA (siRNA)-mediated gene silencing of the components of the MLL1/WDR5 complexes WDR5, MLL1, RBBP5, and ASH2L lead to the accumulation of SOX2, while forced expression of WDR5 promotes SOX2 ubiquitination and proteolysis. Conversely, PHD finger protein 20-like protein 1 (PHF20L1) associates with SOX2, antagonizes SOX2 ubiquitination and the sequential degradation induced by the MLL1/WDR5 complexes. RNA interferences of PHF20L1 promote the degradation of SOX2, while forced expression of PHF20L1 stabilizes SOX2. Co-silencing of MLL1/WDR5 components and PHF20L1 preclude degradation of SOX2 induced by knockdown of PHF20L1. Moreover, co-expression of PHF20L1 and WDR5 prevent ubiquitination of SOX2 triggered by WDR5 overexpression. However, SOX2 mutant K42R is non-sensitive to the MLL1/WDR5 complexes or PHF20L1. In addition, PHF20L1 may regulate the stability of SOX2 through its malignant brain tumor (MBT) domain, since the degradation of SOX2 is accelerated by UNC1215 and UNC669, inhibitors that bind to the MBT domain. Furthermore, abundant expression of SOX2 is highly correlated to immature ovarian teratoma. Loss of PHF20L1 weakened the tumor initiation ability of PA-1 cells while ablation of MLL1 promoted the growth of tumors. Thus, our studies reveal an antagonistic mechanism by which the protein stability of SOX2 is regulated by the MLL1/WDR5 complexes and PHF20L1, possibly through methylation of SOX2 protein, and provide a novel perspective on SOX2-positive cancer treatment.
\end{abstract}

\section{Introduction}

SOX2 is a key stem cell factor belonging to the SRY-related HMG box protein family. It plays vital roles in embryonic

These authors contribute equally: Qianqian Wang, Min Yu.

Electronic supplementary material The online version of this article (https://doi.org/10.1038/s41374-018-0106-8) contains supplementary material, which is available to authorized users.
Hui Zhang
hui.zhang@unlv.edu
$\bowtie$ Rongfeng Lan
lan@szu.edu.cn
lufei@pkusz.edu.cn

$\triangle$ Fei Lu

Extended author information available on the last page of the article development, maintenance of stem cells, and formation of induced pluripotent stem cells (iPS) [1-3]. The amplification of $S O X 2$ gene occurs in a number of cancers, including glioblastoma, small cell carcinoma and squamous cell carcinoma of lung, esophageal squamous cell carcinomas, and oral squamous cell carcinomas [4-11]. Moreover, SOX2 is related to the maintenance of pluripotency and self-renewal of cancer stem cells [4, 12-21] and plays a crucial role in tumorigenesis. The expression of SOX2 is transcriptionally regulated by Oct3/4, NANOG, SMAD1, START1, E2F3, LSD1, HDAC1, and p21 [22-26]. In addition, posttranslational modifications such as methylation and phosphorylation reveal novel mechanism on determining SOX2 stability and functions in stem cell maintenance or differentiation [27-29].

Mixed-lineage leukemia or myeloid/lymphoid (MLL1), also known as histone-lysine $N$-methyltransferase $2 \mathrm{~A}$ (KMT2A), acute lymphoblastic leukemia 1, or HRX (zinc 
finger protein $\mathrm{HRX}$ ), is encoded by gene $K M T 2 A$ in humans. KMT2A encodes a transcriptional coactivator that plays an essential role in regulating gene expression during early development and hematopoiesis. Multiple chromosomal translocations of KMT2A can cause certain acute lymphoid leukemia and acute myeloid leukemia [30]. MLL1 contains several domains, such as plant homodomain (PHD), bromo domain, CXXC domain, and SET domain. The SET domain catalyzes the methylation of H3K4, a chromatin modification associated with epigenetic transcriptional activation. MLL1 can be cleaved by Taspase I and generate $320 \mathrm{kDa}$ N-terminal (MLL-N) and $180 \mathrm{kDa}$ Cterminal (MLL-C) fragments, which then dimerize in a large-molecular-weight complex [31, 32]. The MLL-C core complex that mediates $\mathrm{H} 3 \mathrm{~K} 4$ methylation consists of key components like WD-40 repeat protein 5 (WDR5), ASH2 (absent, small, or homeotic)-like (Drosophila) (ASH2L), and retinoblastoma-binding protein 5 (RBBP5). WDR5 mediates the binding of the MLL complex to H3K4 and this is important for the conversion of di- to tri-methyl groups at lysine 4 (H3K4), while RBBP5 stabilizes the interaction between MLL-C and WDR5 as well as ASH2L. The absence of any member of this complex results in a significant decrease of methyltransferase activity or a change of substrate specificity $[33,34]$.

Plant homeodomain finger protein 20-like 1 (PHF20L1) is amplified and over-expressed in aggressive basal-like breast cancer or luminal B breast cancer [35]. PHF20L1 elevation is associated with poor prognosis and shorter survival in breast cancer patients. Experimentally reduced expression of PHF20L1 in PHF2OL1-amplified breast cancer cells could inhibit cell proliferation [35]. Moreover, PHF20L1 can recognize methylated DNMT1 through its MBT domain, and antagonizes DNMT1 degradation [36], promoting tumor development. In this work, we present evidence for a novel antagonistic relationship on the regulation of SOX2 protein stability by MLL1/WDR5 methyltransferase and PHF20L1. The MLL1/WDR5 complexes interact with SOX2 and might methylate SOX2 at lysine 42 , trigger sequential ubiquitination and degradation of SOX2. In the opposite way, PHF20L1 recognizes methylated SOX2, might associate with SOX2 through MBT domain, and inhibits its ubiquitination and sequential degradation.

\section{Materials and methods}

\section{Antibodies and western blotting}

Anti-SOX2 (A301-741), WDR5 (A302-430A), RBBP5 (A300-931A), and MLL1 (A300-374A) antibodies were from Bethyl Laboratories Inc.; anti-PHF20L1
(HPA028417), anti-Flag (F1804), and anti-Tubulin (T4026) antibodies were from Sigma-Aldrich Co. LLC.; anti-ASH2L antibody (\#5019) from Cell Signaling Technology; anti-hemagglutinin (anti-HA) antibody (RG001010) from Beijing Solarbio Science \& Technology Co., Ltd.; and anti-Cullin-1 antibody was laboratory made using purified antigen as described [37]. For western blotting, cellular proteins were quantified, equally loaded, SDSpolyacrylamide gel electrophoresis separated, transblotted, and antibody-probed. Densitometry measurements of protein bands were carried out by Gel Image System 1D analysis software (version 4.2, Tanon Science \& Technology Co. Ltd.). The relative protein levels of SOX2 were normalized to the unrelated loading control Cullin-1 or Tubulin. The density of protein bands from three independent experiments were analyzed to obtain the average values and standard deviation (mean $\pm \mathrm{SD}$ ).

\section{Chemicals and small RNA interferences}

UNC1215 (CAS: 1415800-43-9), UNC669 (CAS: 1314241-44-5), and puromycin (\#S7417) were from Selleck Chemicals. The sequences of the small interfering RNAs (siRNAs) are WDR5-1: 5'-CAGAGGAUAACCUUGUU UA-3', WDR5-2: 5'-GCTGGGAATATCCGATGTA-3', RBBP5-1: 5'-GAUCGAAUAAUCAGAGUUU-3', RBB P5-2: 5'-CCTCCAATATTGGTTCATT-3', ASH2L-1: 5'-GAGAUGUAUUCUUGGUAAA-3', ASH2L-2: 5'-CA AGGACUUUCUGGGAAUA-3', MLL1-1: 5'-GCUGGUC GUUUACUAUAUA-3', MLL1-2: 5'-CCAGUAGACUA GCUGUUAU-3'，PHF20L1-1: 5'-UGGGGUUGAUGGU GCUGAA-3' ${ }^{\prime}$, and PHF20L1-2: 5'-GCAAGAUGUUGGUC CAUUU- $3^{\prime}$.

\section{Cell culture and transfection}

Human ovarian teratocarcinoma PA-1 cells, lung squamous cell carcinoma NCI-H520 cells, and embryonic kidney epithelial 293 cells were purchased from American Type Cell Collection. PA-1 cells were cultured in minimum essential medium (MEM), NCI-H520 cells were cultured in RPMI-1640 medium and 293 cells were maintained in Dulbecco's modified Eagle medium at $37^{\circ} \mathrm{C}, 5 \% \mathrm{CO} 2$ incubator. All medium was supplemented with $10 \%$ fetal bovine serum (FBS), $100 \mathrm{U} \mathrm{mL}^{-1}$ penicillin, and $100 \mu \mathrm{gL}^{-1}$ streptomycin.

For siRNA-mediated gene silencing, cells were transfected with $50 \mathrm{nM}$ siRNAs for $48 \mathrm{~h}$ using DharmaFECT Transfection Reagent (\#T-2001-03, Thermo Fisher Scientific Inc.) according to the manufacturer. To prevent potential off-target effects, two pairs of siRNAs were designed for each gene. All siRNA experiments were repeated three times to obtain the consistent results. 


\section{Site-directed mutation}

The plasmid pMSCV-3Flag3HA-SOX2 was used as a PCR template for site-directed mutation using specific primers. PCR products were incubated with DpnI (\#1235B, Takara Biotechnology Co. Ltd, Dalian) to remove the template from the mutated DNA, and transfected into competent cell DH5 $\alpha$. Positive clones were sequenced to confirm the success of mutation. The sequences for primers used in site-directed mutation were listed in Supplementary Table S3.

\section{Chromatin immunoprecipitation}

Chromatin immunoprecipitation (ChIP) assays were carried out according to the protocol described previously [23]. Briefly, proteins were crosslinked to DNA by formaldehyde and then cells were lysed in ChIP buffer (50 mM HEPES$\mathrm{KOH}$ (pH 7.5), $140 \mathrm{mM} \mathrm{NaCl}, 1 \mathrm{mM}$ EDTA (pH 8.0), $1 \%$ Triton X-100, $0.1 \%$ sodium deoxycholate, $0.1 \%$ SDS, and protease inhibitors). The crosslinked lysate was sonicated to generate DNA fragments of $\sim 500$ bp in average, and soluble chromatin fragments were incubated with anti-SOX2 antibody or rabbit IgG overnight. Immunoprecipitation complexes were eluted and reversed in elution buffer (1\% SDS and $100 \mathrm{mM} \mathrm{NaHCO} 3)$ at $65^{\circ} \mathrm{C}$ to isolate DNA. Purified DNA was used for quantitative PCR (qPCR) to detect the binding of SOX2. GAPDH was taken for normalization. The sequences for primers were listed in Supplementary Table S4.

\section{Real-time qPCR}

Total RNA was extracted using RNAiso Plus (\#9109, Takara Biotechnology Co. Ltd., Dalian), and reverse transcripted into cDNA by Reverse Transcriptase M-MLV (RNase H-) (\#2641 A, Takara Biotechnology Co. Ltd., Dalian). The mRNA levels of target genes were quantified by SYBR Fast qPCR Mix (\#RR430S, Takara Biotechnology Co. Ltd., Dalian) in a CFX Connect Real-Time PCR Detection System (\#1855200, Bio-Rad Laboratories, Inc.). GAPDH was taken for normalization. The sequences for primers were listed in Supplementary Table S5.

\section{Co-immunoprecipitation}

Cells were lysed at $4{ }^{\circ} \mathrm{C}$ for $15 \mathrm{~min}$ in lysis buffer $(0.5 \%$ NP40, $50 \mathrm{mM}$ Tris- $\mathrm{HCl}(\mathrm{pH} 7.5), 150 \mathrm{mM} \mathrm{NaCl}$, protease, and phosphotase inhibitors), and centrifuged twice at $4{ }^{\circ} \mathrm{C}$ for $10 \mathrm{~min}$. The supernatant was incubated with $3 \mu \mathrm{g}$ primary antibodies overnight at $4{ }^{\circ} \mathrm{C}$, and further incubated with $25 \mu \mathrm{L}$ protein-A sepharose beads for $3 \mathrm{~h}$ to pull down the immunoprecipitation complexes.

\section{Ubiquitination assay}

293 cells stably expressing GFP-SOX2 or GFP-SOX2 K42R mutant were co-transfected with pRK5-HA-ubiquitin, pCMV10-3Flag, pCMV10-3Flag-WDR5, or pCMV103Flag-PHF20L1. Forty-eight hours after transfection, cells were treated with $5 \mu \mathrm{g}$ MG-132 for $6 \mathrm{~h}$, and harvested for co-immunoprecipitation. Ubiquitinated proteins were detected by anti-HA antibody.

\section{Tissue microarray and immunohistochemistry}

Human ovarian teratoma tissue microarray (\#OV805, Alenabio Company, Shanxi, China) contains 65 mature teratoma specimens, 8 immature teratoma tissues, and 4 normal tissues (Supplementary Table S1). Immunohistochemistry (IHC) was performed using horseradish peroxidase/3, 3'-diaminobenzidine (DAB) (ABC) detection IHC Kit (ab64261, abcam) and EliVisionTM plus kits (\#KIT-9902, MXB Bio). The slides were heated at $60^{\circ} \mathrm{C}$ for $30 \mathrm{~min}$, deparaffinized in xylene, rehydrated with ethanol, and immersed in methanol with $3 \% \mathrm{H}_{2} \mathrm{O}_{2}$ (hydrogen peroxide) for $10 \mathrm{~min}$ at room temperature to inactivate endogenous peroxidase. Antigens were heat-retrieved in sodium citrate buffer $(10 \mathrm{mM}$ sodium citrate and $0.05 \%$ Tween 20 , $\mathrm{pH}$ 6.0) at $100^{\circ} \mathrm{C}$ for $8 \mathrm{~min}$. After blocked with $10 \%$ serum for $30 \mathrm{~min}$ at $25^{\circ} \mathrm{C}$, the slides were incubated with primary antibodies against SOX2 (dilution 1:50), WDR5 (dilution 1:300), or PHF20L1 (dilution 1:100) overnight at $4{ }^{\circ} \mathrm{C}$. Incubated with biotin-conjugated secondary antibody for $20 \mathrm{~min}$ at $25^{\circ} \mathrm{C}$, the sections were stained with $\mathrm{DAB}$ and counterstained in hematoxylin. For each specimen, the percentage of positive cells was scored as $0(0 \%)$, $1(<25 \%), 2(25-49 \%)$, or $3(>50 \%)$, and the staining intensity was scored as 0 (no staining), 1 (weak staining), 2 (moderate staining), or 3 (strong staining). Under integrative evaluation on the percentage of positive cells and the staining intensity, the criteria for final IHC score was established as: 0 (negative, - ); 1-2 (weakly positive, + ); 3-4 (moderately positive, ++ ); or 5-6 (strongly positive, +++$)$.

\section{The soft agar colony formation assay}

After transfected with luciferase, PHF20L1, MLL1, and PHF20L1 + MLL1 siRNAs for $48 \mathrm{~h}$, PA-1 cells were trypsin-dispersed and plated in agar-coated culture dishes as described [38, 39]. In brief, single-cell suspensions of 10000 cells were plated per $35-\mathrm{mm}$ culture dish in $1.5 \mathrm{~mL}$ of MEM containing 10\% FBS, and $0.34 \%$ agar (A1296, Sigma-Aldrich) on a layer of $2 \mathrm{~mL}$ of the same medium containing $0.7 \%$ agar. Plates were fed twice a week with $0.2 \mathrm{~mL}$ of MEM containing 10\% FBS. Three weeks after 
plating, colonies were stained with $0.05 \%$ crystal violet at room temperature for $2 \mathrm{~h}$, and photographs of the stained colonies were taken by camera or captured under microscope.

\section{Xenograft mouse model}

A total of 24 nonobese diabetic/severe combined immunodeficiency (NOD/SCID) mice (female, 4 weeks) were purchased from Beijing Vital River Laboratory Animal Technology Co., Ltd. and housed conventionally (room temperature, $20 \pm 2{ }^{\circ} \mathrm{C}$; humidity, $55 \%$; 15 air changes per $\mathrm{h}$ and a 12-h light-dark cycle) in polycarbonate cages on hardwood bedding and acclimatized for at least 7 days prior to experiment. All experimental procedures were approved by the Animal Care and Use Committee of Peking University Shenzhen Graduate School (Shenzhen, China). Mice were divided into three groups, each group contained 8 mice. To avoid the difference between control group and experimental group resulted from individual difference, each mouse was transplanted with two kinds of cells, $5 \times 10^{6}$ luciferase siRNA-treated PA-1 cells (siLUC) at left side and $5 \times 10^{6}$ PHF20L1 or MLL1 siRNA-treated PA-1 cells (siPHF20L1, siMLL1, and siMLL1 + siPHF20L1) at right side $24 \mathrm{~h}$ after transfection. Four weeks later, mice were sacrificed and tumors were dissected. The volumes of tumors were calculated using the formula $V=$ length $\times$ width $\times$ height $\times \pi / 6$.

\section{Statistical analysis}

All experiments were performed at least three times except the immunochemical staining of tissue array. For each experiment, triplicates were performed in real-time PCR and western blotting. Data were presented as mean \pm $\mathrm{SD}$. The mean was generated from three independent experiments and SD was the standard deviation. Paired two-side Student's $t$-test was performed to measure the significance of the difference between control group and experimental group, and $p<0.05$ was considered as significant. * Denotes $p<0.05$, ** denotes $p<0.01$, and $* * *$ denotes $p<0.001$. GraphPad Prism 5.0 was used to generate the plots.

\section{Results}

\section{SOX2 is a short-lived protein}

SOX2 is abundantly expressed in PA-1 cells (human ovarian teratocarcinoma). In order to examine the protein stability of SOX2, PA-1 cells were treated with cycloheximide $\left(\mathrm{CHX}, 100 \mu \mathrm{g} \mathrm{mL}^{-1}\right)$, an inhibitor of protein synthesis in eukaryotes. We found that the protein level of SOX2 was remarkably reduced within $4 \mathrm{~h}$ (Fig. 1a), suggesting that SOX2 is a short-lived protein. On the contrary, the protein level of SOX2 was significantly accumulated when cells were incubated with $26 \mathrm{~S}$ proteasome inhibitor MG-132 (5 $\left.\mu \mathrm{g} \mathrm{mL}^{-1}\right)$, with nearly twofold increase within $4 \mathrm{~h}$ (Fig. 1b). According to our previous data [40], SOX2 was highly expressed in NCI-H520 cells (human lung squamous cell carcinoma). We further examined the stability of SOX2 in NCI-H520. Consistently, SOX2 was stabilized by MG-132 and rapidly degraded under CHX treatment in NCI-H520 cells (Figure S1). Therefore, SOX2 is a short-lived protein and the proteasome pathway regulates its protein stability.

\section{SOX2 interacts with the MLL1/WDR5 methyltransferase complexes}

SOX2 is proposed to be regulated by multiple posttranslational modifications such as methylation, acetylation, or phosphorylation. In order to explore the proteins that may regulate $\mathrm{SOX} 2$, we performed anti-SOX2 coimmunoprecipitation to test its potential binding to protein modification enzymes. Interestingly, we detected the prominent association of the methyltransferase complexes MLL1/WDR5 with SOX2 in the SOX2 immunocomplexes (Fig. 1c). As shown in Fig. 1c, the main components of the MLL/WDR5 complexes, such as WDR5, RBBP5, ASH2L, and MLL1, were associated with SOX2 in reciprocal immunoprecipitation, suggesting that the MLL1/WDR5 complexes physically interact with SOX2.

\section{The MLL1/WDR5 complexes regulate the protein stability of SOX2}

It is established that methyltransferase SET7 can methylate SOX2 at lysine 117 (K117), and promote the ubiquitindependent degradation of SOX2 [27]. Considering the direct interaction of the MLL1/WDR5 complexes with SOX2, we proposed the possibility that the MLL1/WDR5 complexes may methylate SOX2 as a new mechanism to regulate the protein stability of SOX2. To test the hypothesis, we knocked down WDR5, RBBP5, ASH2L, or MLL1 using their gene-specific siRNAs respectively and measured the changes of SOX2 protein in both PA-1 and NCI-H520 cells (Fig. 2a, b and S2). The results suggested that downregulation of WDR5, RBBP5, ASH2L, and MLL1 was capable of inducing significant accumulation of SOX2, as compared with that of a luciferase siRNA control (Fig. 2a, b and S2). Conversely, forced expression of exogenous WDR5 was sufficiently reduce the protein level of SOX2 (Fig. 2c). The aforementioned results 

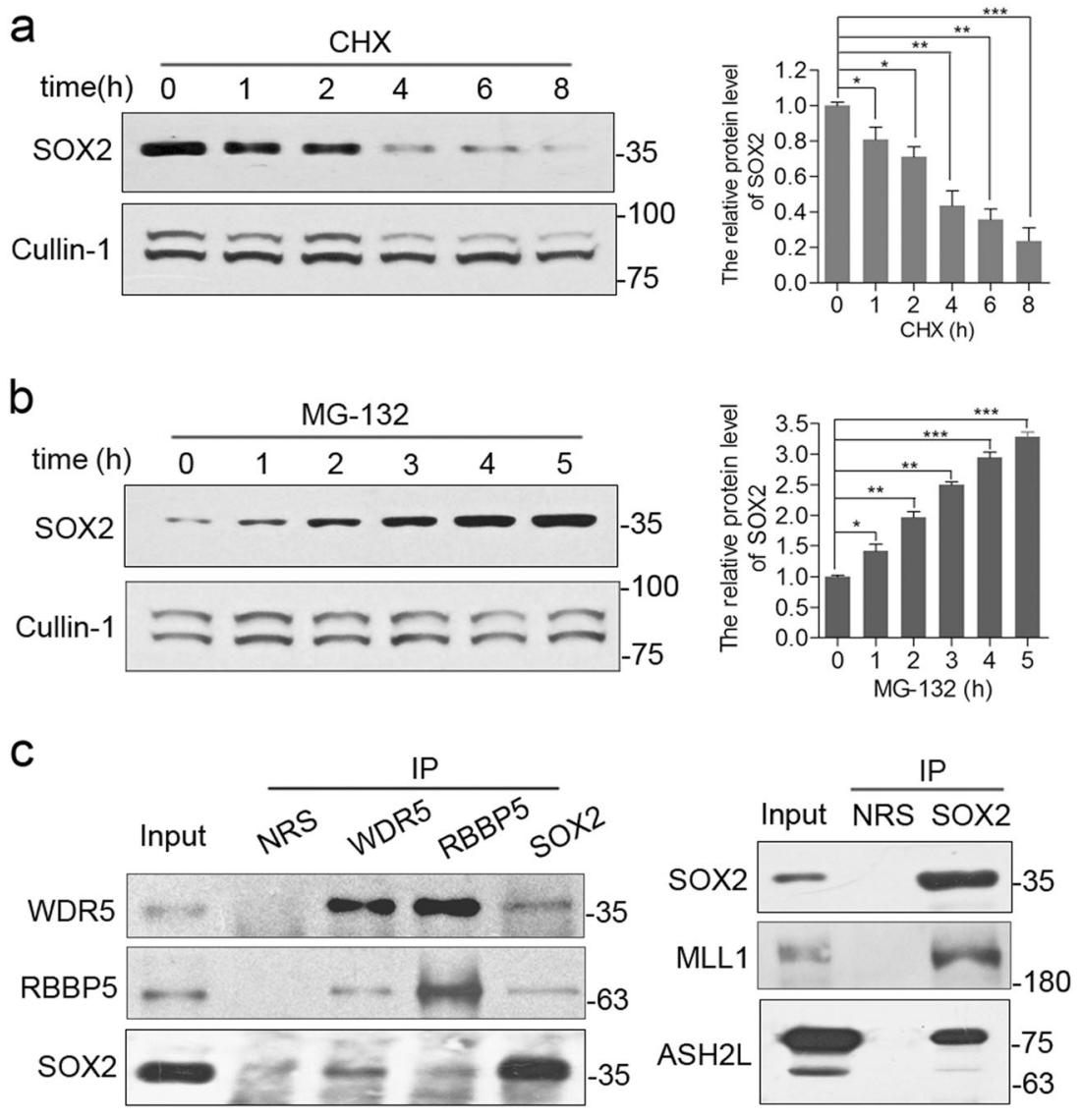

Fig. 1 The methyltransferase complexes MLL1/WDR5 interact with SOX2. a SOX2 was a short-lived protein. SOX2 protein was rapidly decreased upon inhibition of cellular protein synthesis by cycloheximide (CHX, $100 \mu \mathrm{g} \mathrm{mL}^{-1}$ ). Unrelated protein Cullin-1 was blotted as a loading control. Densitometry measurements of blots illustrated the relative protein level of SOX2 upon CHX treatments. b Inhibiting the activity of $26 \mathrm{~S}$ proteasome promoted the accumulation of SOX2. PA-1 cells were incubated with $5 \mu \mathrm{gL}^{-1}$ MG-132 as indicated, and

suggested that the MLL1/WDR5 complexes could destabilize SOX2 protein.

It is well established that the MLL1/WDR5 complexes methylate histone $\mathrm{H} 3 \mathrm{~K} 4$, thereby conferring a transcriptionally active chromatin state for gene activation $[33,41]$. Since the MLL1/WDR5 complexes are associated with gene activation, it is surprising that downregulation of the MLL1/WDR5 complexes caused the accumulation of SOX2. To test the possible regulation of SOX2 at the transcriptional level by the MLL1/WDR5 complex, we knocked down WDR5, RBBP5, ASH2L, or MLL1 using gene-specific siRNAs and measured the mRNA levels of SOX2 by quantitative real-time PCR. As showed in Fig. 2d, inactivating the MLL1/WDR5 methyltransferase complexes did not impair the mRNA level of SOX2. The results indicated that the MLL1/WDR5 complexes might regulate the protein stability of SOX2 at post-translational level other than its canonical transcriptional activity. harvested for western analysis. The data in $\mathbf{a}$ and $\mathbf{b}$ were represented as mean \pm SD. $* p<0.05, * * p<0.01, * * * p<0.001$. c SOX2 physically interacts with the MLL1/WDR5 complexes. PA-1 cells were treated with MG-132 for $3 \mathrm{~h}$, and then subjected to co-immunoprecipitation using antibodies against WDR5, RBBP5, SOX2, and NRS (normal rabbit serum as a control). The interactions between SOX2 and WDR5, RBBP5, ASH2L, and MLL1 were examined by western blotting

\section{The MLL1/WDR5 complexes regulate SOX2 through K42 to promote its ubiquitination}

According to the sequence alignment of the WDR5-binding motif, such as the N-terminal tail of histone H3, Win domain of MLL1, and Ala12-Pro17 peptides of WDR5, WDR5 prefers to bind a peptide motif containing the "R/KXK" sequence (Fig. 3a), in which the amino acid arginine (R) residue is crucial for the specific recognition and binding of WDR5, and methylation usually occurred on the adjacent lysine $(\mathrm{K})[34,42]$. To test this possibility, we identified motifs that contain the consensus "R/KXK" in SOX2, which included K42, K117, K121, K122, and K124 (Fig. 3a). To test the potential functions of these lysine residues on SOX2 stability, we mutated each of these lysine residues to arginine and ectopically expressed each of them, as well as the wild-type SOX2, as Flag-tagged proteins under the retroviral LTR promoter control in PA-1 cells. We 

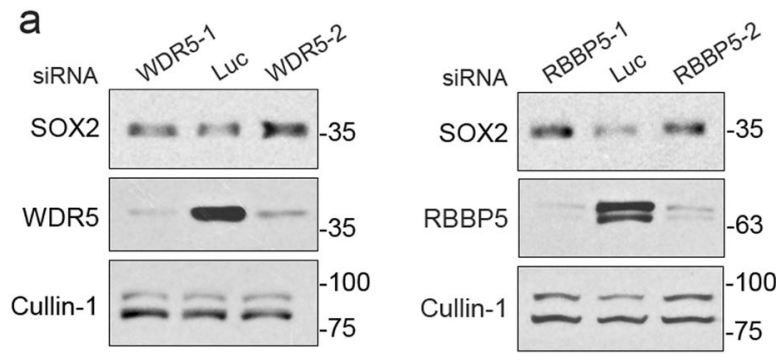
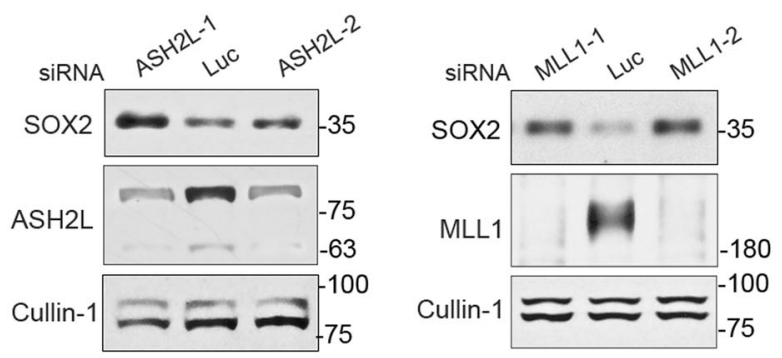
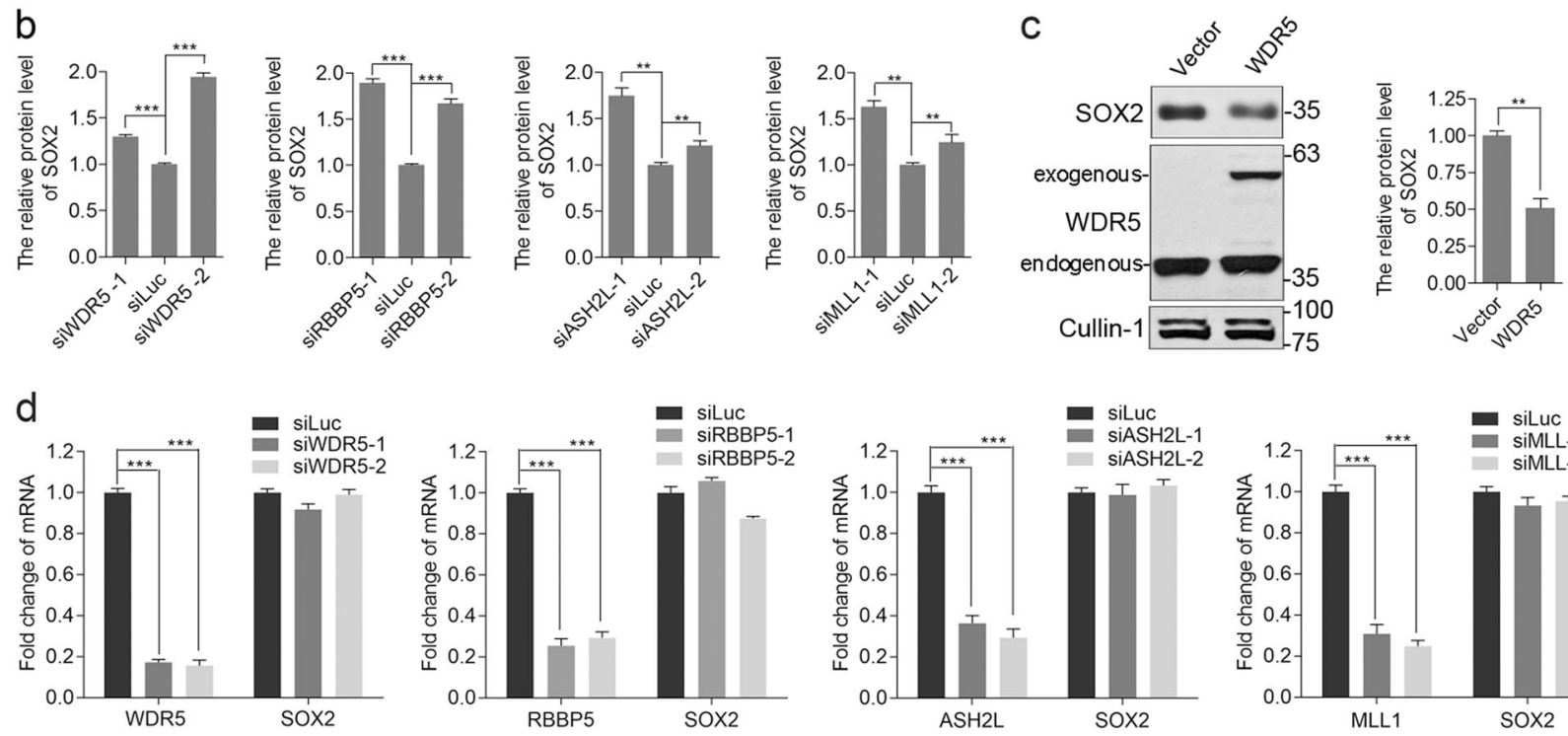

Fig. 2 Inhibiting the activity of the MLL1/WDR5 complexes stabilize SOX2. a SiRNA-mediated knockdown of the components of the MLL1/WDR5 complexes resulted in the accumulation of SOX2. PA-1 cells were transfected with two pairs of specific siRNAs targeting WDR5, RBBP5, ASH2L, or MLL1 respectively for $48 \mathrm{~h}$. Protein changes were examined by specific antibodies as indicated, and Cullin1 was served as a loading control. b Densitometry measurements illustrating the relative protein level of SOX2 after knockdown of WDR5, RBBP5, ASH2L, or MLL1, which was normalized to Cullin1. c Forced expression of WDR5 decreased the protein level of SOX2.

proposed that the MLL1/WDR5 complexes methylate the candidate lysine residue in SOX2 to promote its proteolysis. If this is the case, the mutant would be non-sensitive to the MLL1/WDR5 complexes, and the protein level of this mutant would not be increased after knockdown of the MLL1/WDR5 complexes. We stably expressed the wildtype SOX2 and the mutants in PA-1 cells using recombinant retroviruses, and then knocked down MLL1 or WDR5 using siRNAs. Upon silencing of MLL1 and WDR5, both endogenous SOX2 and exogenous SOX2 were obviously accumulated except K42R mutant. The fact that the K42R mutant was non-sensitive to the silencing of MLL1 or WDR5 indicated that K42 might be methylated by the MLL1/WDR5 complexes (Fig. 3b).

Furthermore, we tried to determine whether the MLL1/ WDR5 complexes target SOX2 for ubiquitinationdependent degradation. We transfected HA-tagged
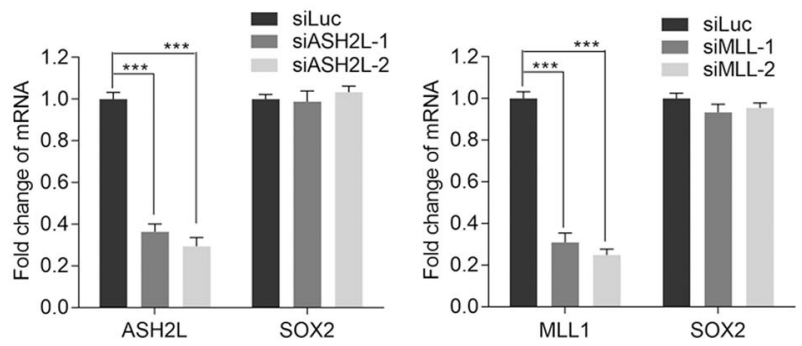

PA-1 cells were transfected with pMSCV-TAP-WDR5 and pMSCVTAP (vector) plasmids, respectively. Forty-eight hours post transfection, proteins of interest were detected using specific antibodies. Densitometry measurements illustrated the relative protein level of SOX2, which was normalized to Cullin-1. d The mRNA levels of SOX2 were stable after knocking down of WDR5, RBBP5, ASH2L, or MLL1. The relative mRNA levels were measured by quantitative real-time PCR after PA-1 cells were transfected with indicated siRNAs for $48 \mathrm{~h} . * * p<0.01, * * * p<0.001$. The data were represented as mean $\pm \mathrm{SD}$

ubiquitin with or without Flag-WDR5 into 293 cells that stably expressing GFP-SOX2. Forty-eight hours post transfection, cells were treated with MG-132 for $6 \mathrm{~h}$ to allow the accumulation of ubiquitinated proteins. SOX2 was subsequently immunoprecipitated by an anti-SOX2 antibody. We found that in the presence of Flag-WDR5, SOX2 is significantly ubiquitinated, which can be detected as high-molecular protein species by the anti-HA antibody (Fig. 3c). These studies provided consistent evidence that the MLL1/WDR5 complexes targeted SOX2 for ubiquitination.

\section{PHF20L1 stabilizes SOX2 through preventing it from proteasomal degradation}

While our aforementioned evidences suggest that SOX2 is likely methylated by the MLL1/WDR5 methyltransferase 
a

H3K4me2 peptide $A T T K Q T$ MLL1 Win peptide A R A E V H SOX2 peptide (39 44) D R V K R P SOX2 peptide(114 119) $\mathrm{R}$ K T K T L SOX2 peptide(121 126) K K D K Y T

C
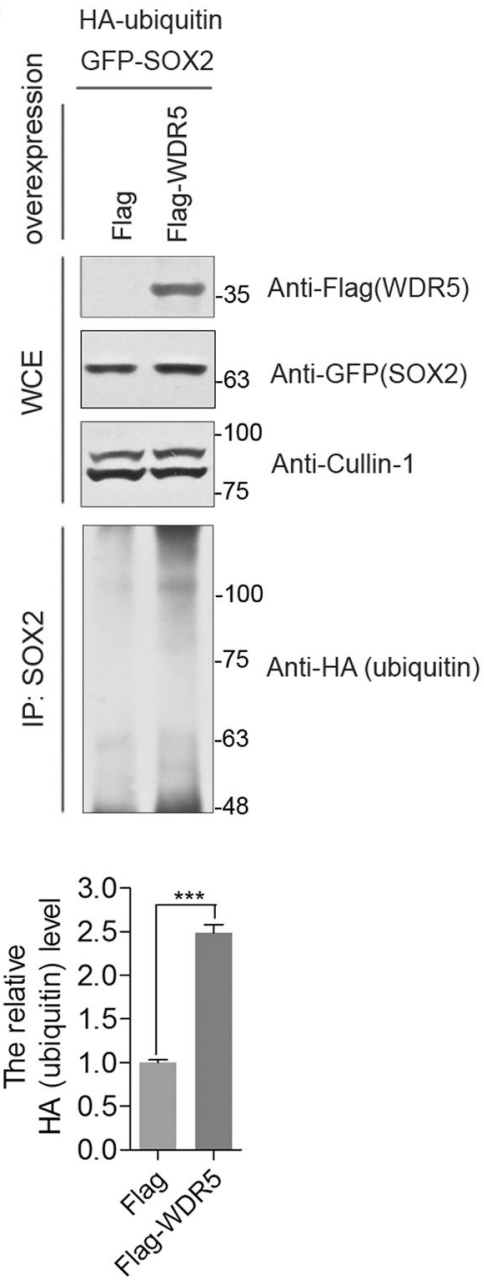

b
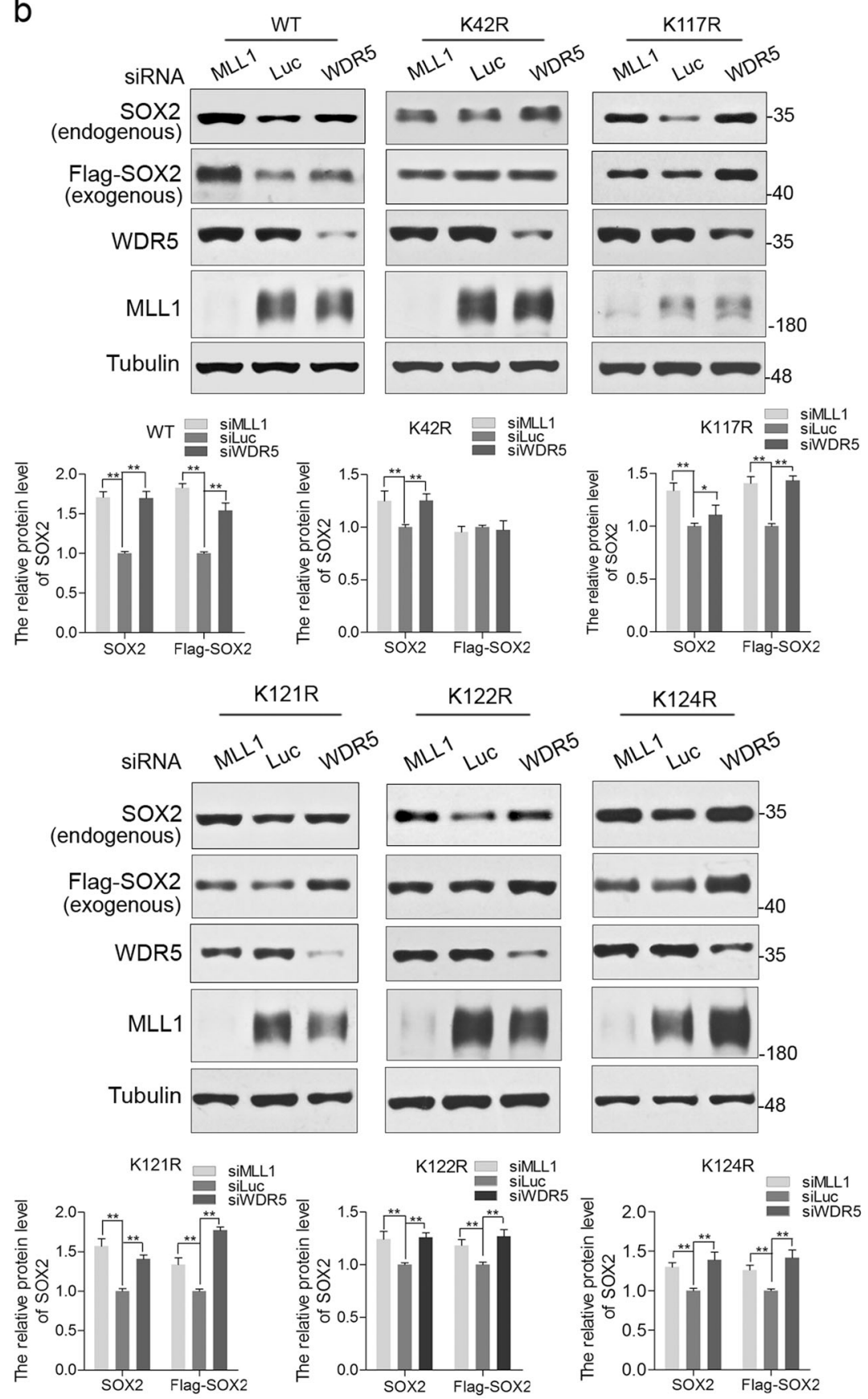

Fig. $3 \mathrm{~K} 42$ is crucial for the degradation of SOX2 induced by the MLL1/WDR5 complexes. a Sequence alignment of SOX2 peptides, histone H3 N-terminal peptide, and the MLL1 Win peptide. b K42R mutant was non-sensitive to the MLL1/WDR5 methyltransferase complexes. Candidate lysines in SOX2 were mutated to arginine. The wild-type SOX2 and mutants were tagged with an N-terminus Flag, and stably expressed in PA-1 cells through retroviral gene transfer and expression system. Cells were harvested after knockdown of MLL1 or WDR5 for $48 \mathrm{~h}$, and proteins of interest were analyzed by western blotting. The relative protein levels of SOX2 were densitometry

complexes, we sought additional evidence to illustrate that SOX2 is methylated and its methylation status regulates the protein stability of SOX2. It was reported that measured and plotted, which were normalized to tubulin. c Forced expression of WDR5 promotes the ubiquitination of SOX2. GFPSOX2 was stably expressed in 293 cells. The cells were co-transfected with pRK5-HA-ubiquitin and pCMV10-3Flag or pCMV10-3FlagWDR5 respectively. MG-132 was applied to accumulate the ubiquitinated proteins. Co-immunoprecipitation was performed using antiSOX2 antibody, and the ubiquitination was analyzed by anti-HA antibody. The ubiquitinated SOX2 was densitometry quantified by Gel Image analysis software. $* p<0.05, * * p<0.01, * * * p<0.001$. The data were represented as mean $\pm \mathrm{SD}$

the MBT domain-containing protein PHF20L1 could recognize the methylated DNMT1 at K142 and its binding to the methylated DNMT1 prevents the proteolysis of 

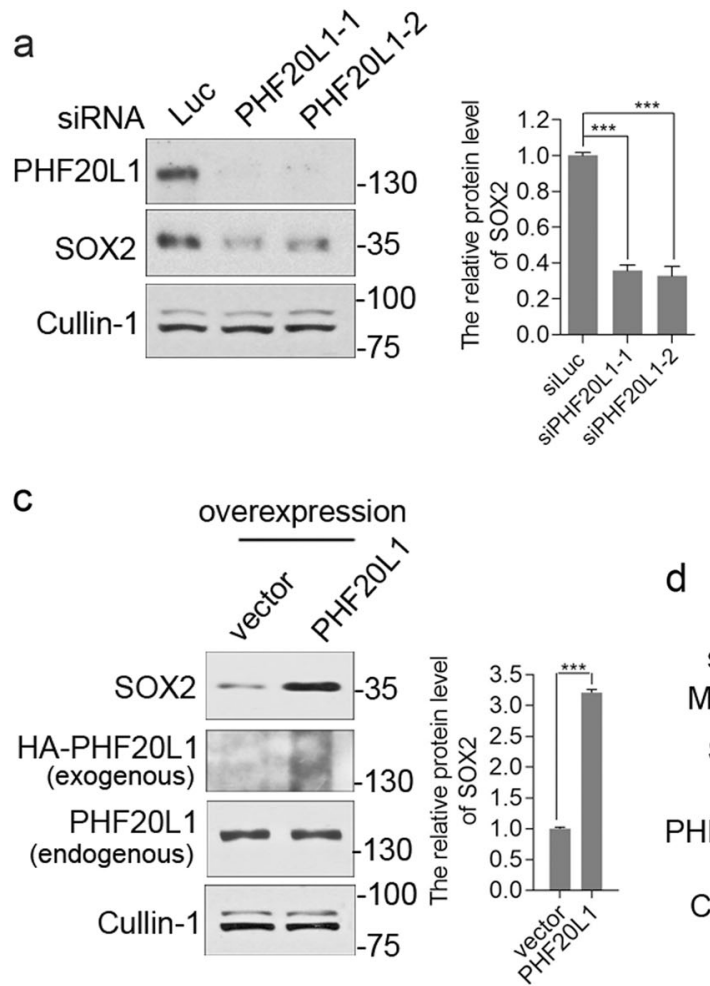

Fig. 4 PHF20L1 antagonizes the degradation of SOX2. a Knockdown of PHF20L1 reduced the protein of SOX2. PA-1 cells were transfected with two specific PHF20L1 siRNAs respectively and then the protein level of SOX2 was western analyzed, densitometry quantified, and plotted, normalizing to Cullin-1. b The mRNA level of SOX2 was negligibly impaired after knocking down PHF20L1. The mRNA level of PHF20L1 and SOX2 were measured by quantitative real-time PCR. Results were normalized to $\beta$-actin. c Over-expression of PHF20L1

DNMT1 [36]. We tried to determine whether PHF20L1 regulated the protein stability of SOX2 by recognizing the methylated SOX2 and preventing SOX2 degradation. The results showed that silencing of PHF20L1 with two independent siRNAs consistently caused the significant reduction of SOX2 (Fig. 4a), whereas there were no significant changes of SOX2 mRNA level after PHF20L1 knockdown (Fig. 4b). Moreover, we found that overexpression of PHF20L1 led to significant accumulation of SOX2 (Fig. 4c). The 26S proteasome inhibitor MG-132 could block the reduction of SOX2 in PHF20L1 knockdown cells (Fig. 4d). Therefore, these results indicated that PHF20L1 plays a protective role for SOX2 and possibly through blocking the ubiquitin-dependent proteolysis of SOX2.

\section{PHF20L1 inhibits the degradation of SOX2 induced by the MLL1/WDR5 complex-mediated methylation}

Since our evidences suggested that SOX2 might be methylated by the methyltransferase complexes MLL1/
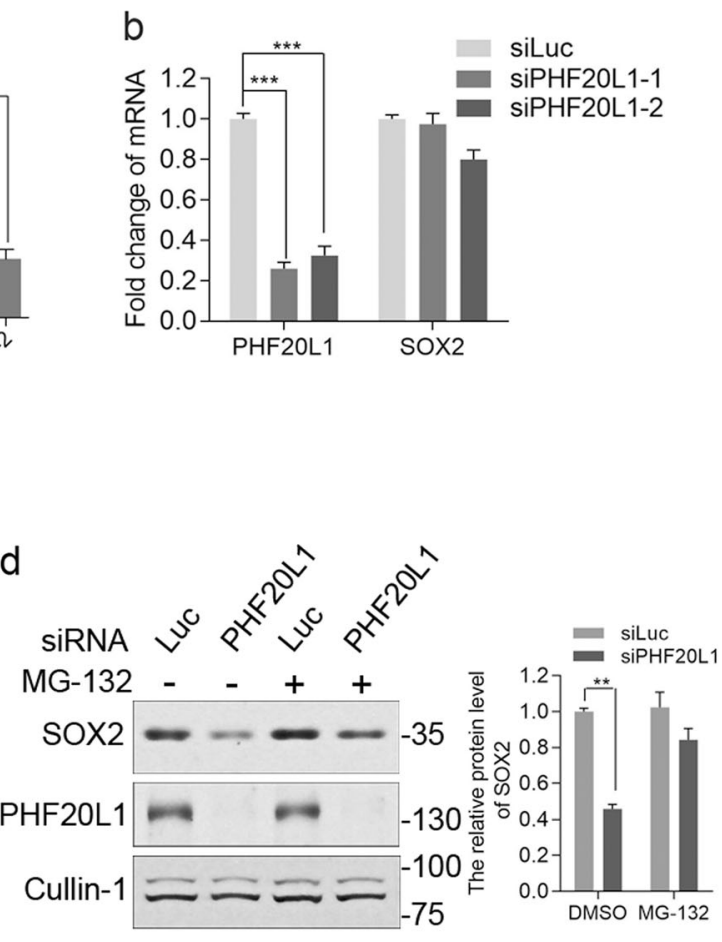

induced the accumulation of SOX2 protein in PA-1 cells. Cullin-1 was blotted as a loading control. Densitometry measurements illustrated the relative protein level of SOX2. d SOX2 degradation after PHF20L1 knockdown was mediated by $26 \mathrm{~S}$ proteasome. PA-1 cells were transfected with control (Luc) or PHF20L1 siRNAs for $48 \mathrm{~h}$, and then incubated with MG-132 for $3 \mathrm{~h}$. The relative protein level of SOX2 was densitometry quantified and plotted. a-d $* * p<0.01 ; * * * p<$ 0.001 . The data were represented as mean $\pm \mathrm{SD}$

WDR5, and PHF20L1 is also known to bind to methylated DNMT1, we tried to determine whether the effect of PHF20L1 on SOX2 stability is mediated through the MLL1/WDR5 complexes. We knocked down PHF20L1 together with the components of the MLL1/WDR5 complexes in either PA-1 or NCI-H520 cells, our results showed that knockdown of WDR5, RBBP5, ASH2L, or MLL1 could partially rescue the reduction of SOX2 caused by PHF20L1 deficiency (Fig. 5a and S3). To further investigate whether PHF20L1 could block the ubiquitination of SOX2 induced by the MLL1/WDR5 complexes, we co-transfected Flag-tagged PHF20L1 and HA-ubiquitin in 293 cells stably expressing GFP-SOX2, with or without Flag-WDR5. In the presence of MG-132, ubiquitinated SOX2 was remarkably enhanced when WDR5 was over-expressed, while coexpression of PHF20L1 along with WDR5 greatly diminished the enhanced ubiquitination of SOX2 (Fig. 5b). Densitometry analysis of the ubiquitinated SOX2 revealed that the ubiquitinated SOX2 elevated 2.5-fold in the presence of WDR5 compared to that of control (Flag lane), but dropped to 1.5-fold of background levels when PHF20L1 
a
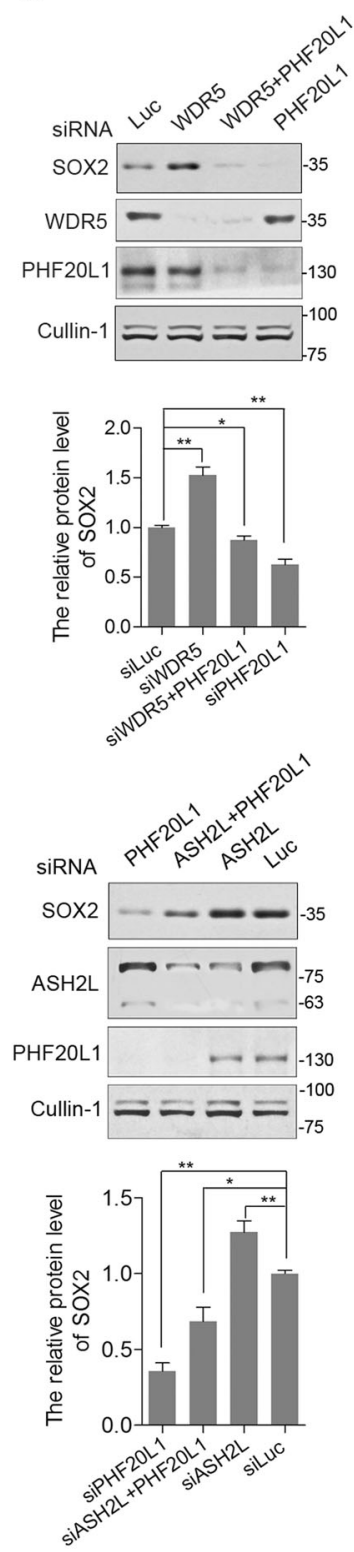
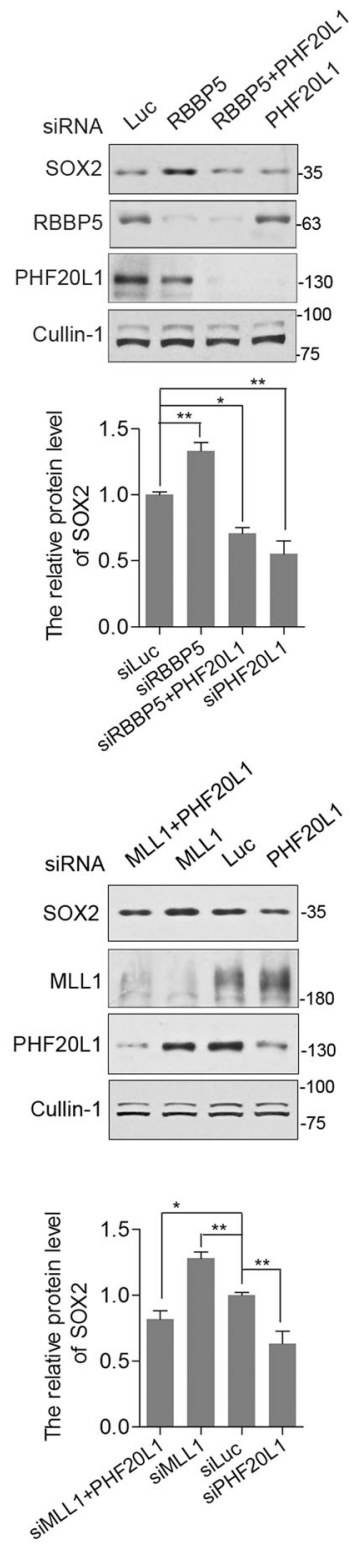

Fig. 5 PHF20L1 inhibits WDR5-dependent ubiquitination of SOX2. a Silencing of PHF20L1 antagonized the accumulations of SOX2 protein induced by knocking down the components of the MLL1/ WDR5 complexes. PA-1 cells were co-transfected with siRNAs targeting WDR5, RBBP5, ASH2L, MLL1, or PHF20L1 respectively for $48 \mathrm{~h}$, and the protein levels of SOX2 were examined by western blotting. The relative protein levels of SOX2 were quantified and plotted on the lower panels respectively. b PHF20L1 inhibited the ubiquitination of SOX2. 293 cells stably expressing GFP-SOX2 or GFP-SOX2-K42R mutant were co-transfected with plasmids encoding HA-ubiquitin, Flag (plasmid vector) or Flag-WDR5, and FlagPHF20L1 for $48 \mathrm{~h}$ respectively. Cells were incubated with MG-132

and WDR5 were co-expressed. Furthermore, we observed the direct interaction between SOX2 and PHF20L1 (Fig. 5c). These results strongly demonstrated that MLL1/ WDR5-mediated SOX2 degradation could be inhibited by PHF20L1.



for $6 \mathrm{~h}$ and SOX2 was immunoprecipitated using anti-SOX2 antibody. Ubiquitinated SOX2 was detected by an anti-HA antibody. The ubiquitinated SOX2 was densitometry quantified and plotted using Gel Image analysis software. a and $\mathbf{b} * p<0.05, * * p<0.01, * * * p<0.001$. The data were represented as mean \pm SD. c SOX2 interacted with PHF20L1. Upper panel: endogenous SOX2 interacted with endogenous PHF20L1 in PA-1 cells. Bottom panel: exogenous SOX2 associated with exogenous PHF20L1 in 293 cells stably expressing GFP-SOX2. Co-immunoprecipitated SOX2 or Flag-PHF20L1 were examined with anti-Flag or SOX2 antibodies respectively. Normal rabbit serum (NRS) was taken as a negative control

\section{The MBT domain of PHF20L1 is required for protecting SOX2 from degradation}

PHF20L1 contains MBT, Tudor-like, and PHD finger domain, all of them are implicated in recognizing the 
methylated lysines. It is reported that PHF20L1 recognizes methylated DNMT1 through its MBT domain and regulates the degradation of DNMT1 [27]. To explore whether the MBT domain of PHF20L1 is required for SOX2 degradation regulation, we used chemical inhibitors UNC1215 and UNC669, which were developed as effective and specific antagonists of MBT domain. These inhibitors were shown to interact with the MBT domain of PHF20L1 [43]. To examine whether the MBT domain of PHF20L1 was involved in SOX2 degradation, we incubated cells with UNC1215 or UNC669 at different doses for $24 \mathrm{~h}$. Our data revealed that the protein level of SOX2 was decreased in a dose-dependent manner (Fig. 6a). However, the mRNA levels of SOX2 were stable under the treatment of these chemicals (Fig. 6b). Thus, our data indicated that the MBT domain of PHF20L1 could read methylated SOX2.

To further determine whether UNC1215 and UNC669 promote the degradation of SOX2 by inhibiting PHF20L1, we treated PA-1 cells with the protein synthesis inhibitor CHX followed by addition of either $40 \mu \mathrm{M}$ UNC1215, UNC669, or dimethyl sulfoxide as solvent control. The results revealed that the half-life of SOX2 was significantly shortened when cells were treated with UNC1215 or UNC669, as compared with that of the control. However, consistent with their roles as competitive inhibitors, UNC1215 and UNC669 did not have any effect on the halflife of PHF20L1 (Fig. 6c). Taken together, our results indicated that the proteasomal degradation of SOX2 is regulated by the MBT domain of PHF20L1, possibly through recognizing methylated lysine residues of SOX2.

\section{High expression of SOX2 is closely related to aggressive teratoma and negatively correlated to WDR5 expression}

We have established that the MLL1/WDR5 complexes and PHF20L1 oppositely regulate the protein level of SOX2. Then, we would like to explore the effects of this regulation on cellular events or disease. First, we asked whether the transcriptional activity of SOX2 was affected by this antagonistic regulation. It is well-known that SOX2 transcriptionally represses expression of FOXA2 and SOX17, but activates expression of KRT6A and TP63 [40]. We examined the mRNA levels of FOXA2, SOX17, KRT6A, and TP63 in PA-1 cells after silencing of MLL1 or PHF20L1. As shown in Fig. 7a, the mRNA levels of FOXA2 and SOX17 were downregulated after knockdown of MLL1, but upregulated after silencing of PHF20L1. Conversely, the mRNA levels of KRT6A and TP63 were upregulated when MLL1 was silenced, but downregulated when PHF20L1 was knocked down (Fig. 7a). To figure out whether the mRNA level changes of these genes were due to the direct binding of SOX2, we carried out ChIP assays using anti-SOX2 antibody. As we expected, SOX2 bound to the promotor or enhancer regions of these genes (Fig. 7b). The enrichment of SOX2 on these regions was dramatically reduced when SOX2 and PHF2011 were silenced, compared to control (luciferase siRNAs), but increased upon knockdown of MLL1 (Fig. 7b). Besides, the stem cell makers OCT4 and Lin 28 were also moderately upregulated when MLL1 was silenced (Figure S4). These results were consistent with the changes of SOX2 protein level. Thus, the protein level alteration of SOX2 oppositely regulated by the MLL1/WDR5 complexes and PHF20L1 can deeply impair the functions of SOX2.

Moreover, as a stemness factor, SOX2 not only regulates self-renewal and pluripotency of stem cells but also closely relates to tumorigenesis. To figure out the relationship among the expression of SOX2, WDR5, and PHF20L1 in tumors, we performed IHC staining on an ovarian teratoma chip using anti-SOX2, anti-WDR5, and anti-PHF20L1 antibodies. As shown in Figure S5 and Table S1-S2, the expression of SOX 2 were undetectable in $100 \%$ of normal tissue, $69.23 \%$ (45/65) of mature teratoma, but expressed in $75 \%(6 / 8)$ of immature teratoma. The results suggested that SOX2 expression was closely related to the aggressive teratomas. Consistent with SOX2, the expression of PHF20L1 was undetectable in normal tissue, but detected in $87.50 \%(7 / 8)$ of immature teratomas. Whereas, WDR5 had the ubiquitous expression pattern, can be detected in $98.7 \%$ (76/77) of the tissues (Table S2). From the magnified images of immature teratoma, we observed that SOX2positive cells were located on the different area, compared to WDR5-positive cells (Fig. 7c). In the area where SOX2 was highly expressed, the expression of WDR5 was much lower, while in the area where WDR5 was highly expressed, the expression of SOX2 was very low (Fig. 7c). To summarize, our data suggested that high expression of SOX2 was closely related to aggressive teratoma and the protein level of SOX2 might antagonistically regulated by the MLL1/WDR5 complexes and PHF20L1 in the tumors.

\section{Silencing of PHF20L1 weakened the tumor initiation ability of PA-1 cells}

Since SOX2 was considered as the driver for tumorigenesis and maintained the stem-like phenotype of cancer cells [44], we evaluated the tumor initiation ability of PA- 1 cells after downregulating SOX2 by ablation of PHF20L1. The soft agar colony formation assay is a well-established anchorage-independent method to characterize cell malignant transformation and carcinogenic capability in vitro. As showed in Fig. 7d, the number of colonies formed after 
a

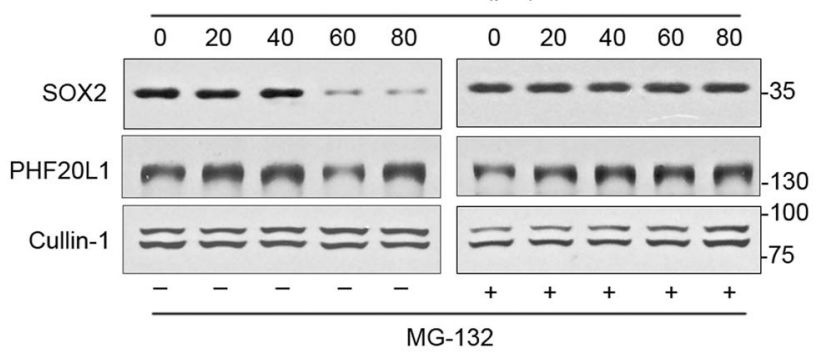

UNC669 $(\mu \mathrm{M})$

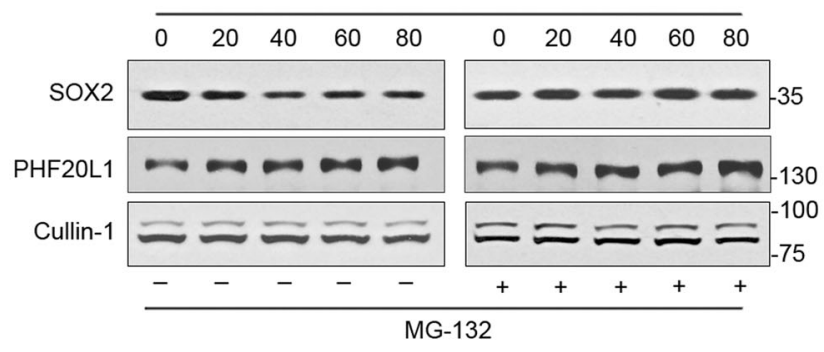

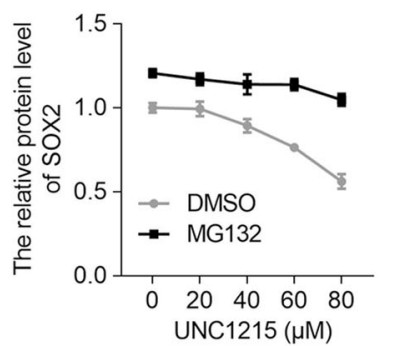

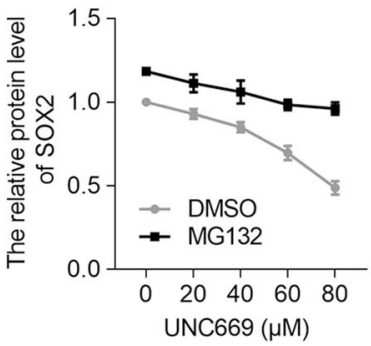

b
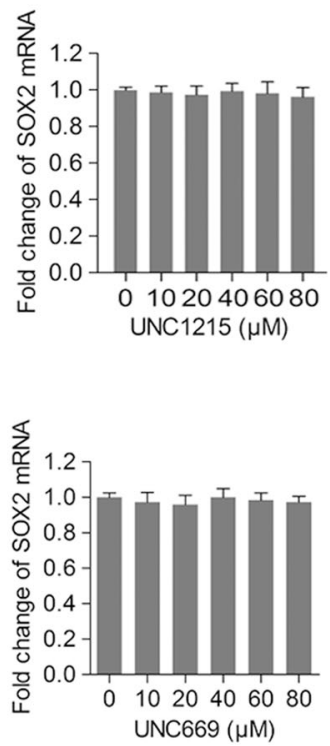

C

$\mathrm{CHX}(\mathrm{h})$
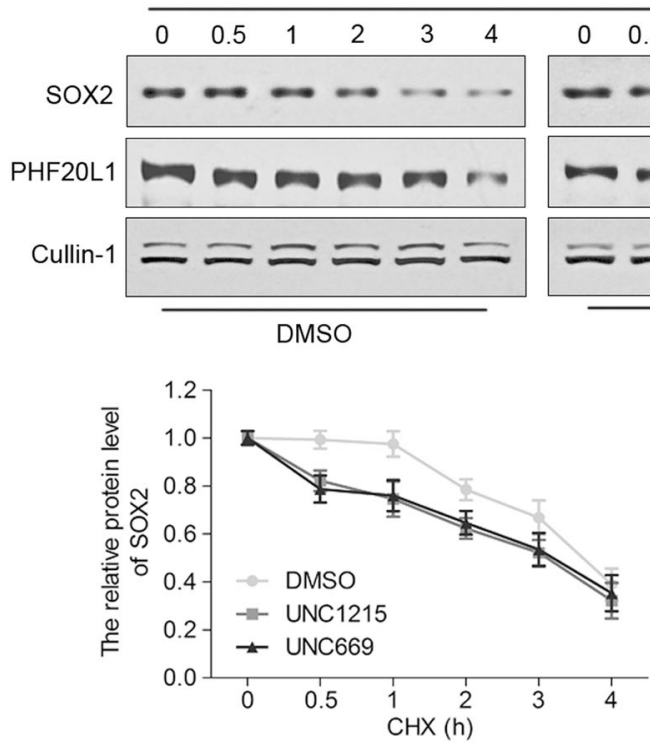

Fig. 6 Blocking the MBT domain of PHF20L1 destabilizes SOX2. a Inhibiting the MBT domain of PHF20L1 with small chemicals UNC1215 and UNC669 destabilized SOX2. PA-1 cells were incubated with UNC1215 or UNC669 for $24 \mathrm{~h}$ and then further treated with either DMSO or MG-132 for $4 \mathrm{~h}$. Densitometry measurements illustrating the relative protein levels of SOX2 and PHF20L1, normalized to Cullin-1, were plotted (right panels). b UNC1215 and UNC669 treatments did not affect the mRNA level of SOX2. Quantitative

PHF20L1 knockdown was remarkably reduced and the sizes of colonies were notably smaller compared with luciferase siRNA treatment. Co-silencing of MLL1 and PHF20L1 could restored the growth of colonies (Fig. 7d). To further investigate the effects of the dichotomization regulation of SOX2 by PHF20L1 and MLL1 on tumor initiation in vivo, we transplanted siRNA-treated PA-1 cells into NOD/SCID mice. The consistent results were obtained and the volumes of tumors derived from PHF20L1 siRNAtreated PA-1 cells were much smaller than those from luciferase siRNA-treated PA-1 cells, but the volumes of tumors from co-silencing of MLL1 and PHF20L1 were 
a

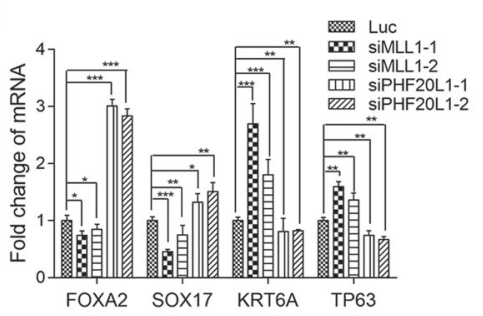

C

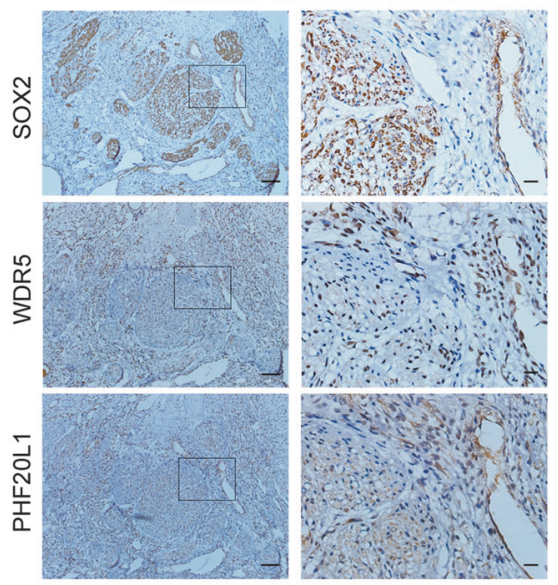

b

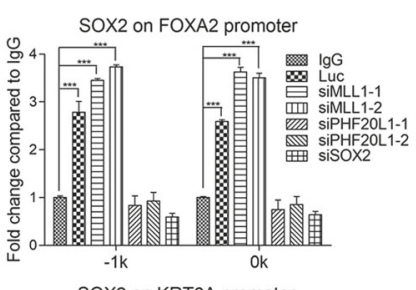

SOX2 on KRT6A promoter

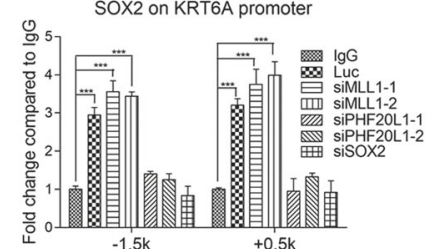

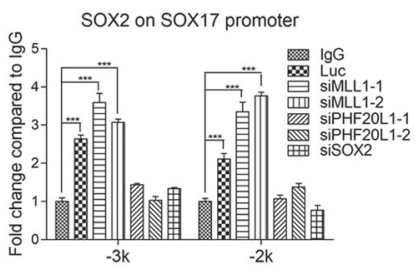

SOX2 on TP63 promoter

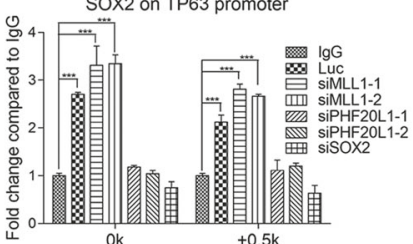

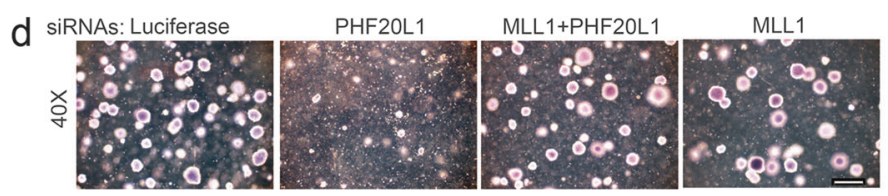

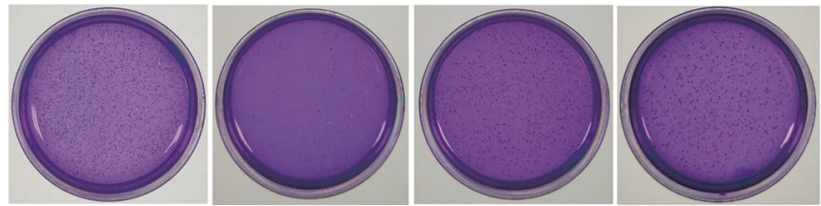

e
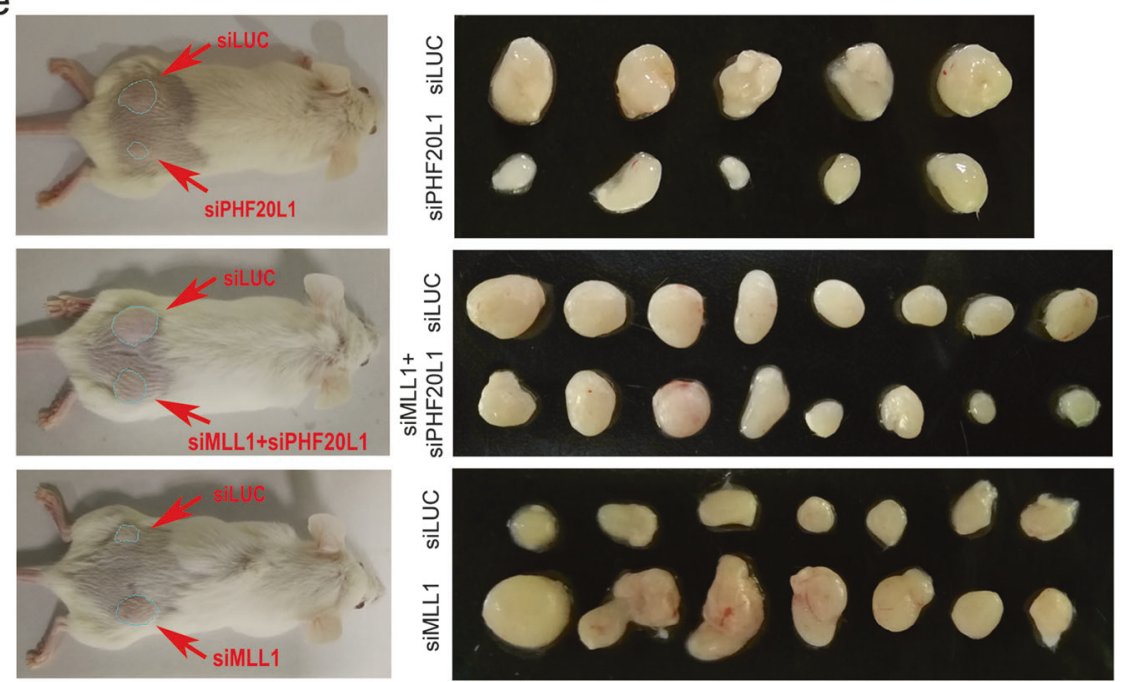

f

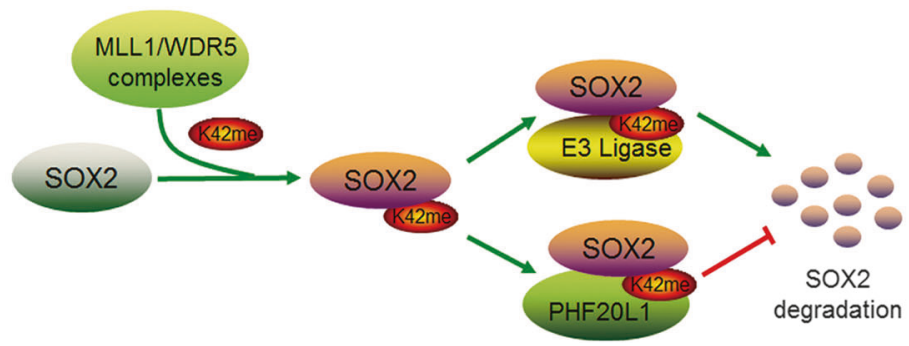

close to control (Fig. 7e). Interestingly, we found that under the same condition, loss of PHF20L1 hindered the development of tumor while knockdown of MLL1 promoted tumor growth (Fig. 7e). Altogether, our data demonstrate that PHF20L1 and MLL1 play opposite function on tumor initiation through regulating $\mathrm{SOX} 2$ proteolysis. 
Fig. 7 The expression of SOX2 is closely related to aggressive teratoma and is negatively correlated to WDR5 expression. a The changes of SOX2 protein level modulated the transcriptional activity of SOX2. The mRNA levels of SOX17, FOXA2, KRT6A, and TP63 were RT-PCR-examined after interference of MLL1 or PHF20L1. b The ChIP assay of SOX2 on the promotor regions of SOX17, FOXA2, KRT6A, and TP63 after knockdown of MLL1, SOX2, or PHF20L1. a and $\mathbf{b} * p<0.05, * * p<0.01, * * * p<0.001$. The data were represented as mean $\pm \mathrm{SD}$. c Representative images of tissue microarray and IHC staining of SOX2, WDR5, and PHF20L1 in ovarian teratoma. Bar: $100 \mu \mathrm{m}$ (20 $\mu \mathrm{m}$ for magnified images). d Silencing of PHF20L1 impaired the colony formation of PA-1 cells. Upper panel: representative images of colonies formed in agar under microscope. Bar: $500 \mu \mathrm{m}$. Lower panel: representative wells showing colonies stained by $0.05 \%$ crystal violet. e Silencing of PHF20L1 slowed the growth of tumors in NOD/SCID mice. Left panel: representative mouse transplanted with PA- 1 cells for 28 days. Left side was subcutaneously injected with $5 \times 10^{6}$ cells treated with LUC siRNAs and right side was transplanted with $5 \times 10^{6}$ cells treated with PHF20L1 or MLL1 siRNAs. Middle panel: tumors detached from NOD/SCID mice. Right panel: the volumes of tumors were measured and plotted. f Illustrated model for the antagonizing regulation on the protein stability of SOX2 co-played by the MLL1/WDR5 complexes and PHF20L1. The methyltransferase complexes MLL1/WDR5 possibly methylates SOX2 at lysine 42 (K42) and promotes its ubiquitination and 26S proteasome-mediated degradation. In contrast, PHF20L1 may recognizes the methylated $\mathrm{K} 42$ (K42me) on SOX2 and prevent it from ubiquitin-dependent degradation

\section{Discussion}

SOX2 is a master regulator of self-renewal and pluripotency maintenance of embryonic stem cells [2, 16]. Forced expression of SOX2 along with Oct3/4, KLF4, and c-Myc can reverse somatic cells into iPS [3]. SOX2 gene amplification or protein over-expression was observed in cancers $[20,21,45]$. We also revealed that SOX2 confers sensitivity to LSD1 inhibition in SOX2-positive cancer cells [40]. Therefore, the expression of SOX2 is strictly controlled at transcriptional level and post-translational level, such as acetylation, methylation, and phosphorylation. Wong et al. found that the protein stability of SOX2 is regulated by balanced methylation and phosphorylation switch in mouse embryonic stem cells [27]. The E3 ligase WWP2 specifically interacts with K119 methylated mouse SOX2, which is in turn methylated by SET7 to promote SOX2 ubiquitination. In contrast, AKT1 phosphorylates SOX2 at T118 and stabilizes SOX2 by antagonizing K119 methylation [27]. In addition, we found that the mitotic phosphorylation of SOX2 on Ser250/Ser251 by Aurora A kinase is critical for stem cell maintenance [28]. In this study, we unveiled an antagonistic mechanism on regulating SOX2 protein stability by the MLL1/WDR5 complexes and PHF20L1.

The methyltransferase complexes MLL1/WDR5 directly interact with SOX2 and likely methylate SOX2 at lysine 42 (K42), resulting in its ubiquitination and proteasomal degradation (Figs. 1 and 2, Figure S1, and Figure S2).
K42R mutant could obviously abolish the ubiquitination of SOX2 (Fig. 3). Thus, methylated K42 may serve as a signal to trigger SOX2 for ubiquitination and subsequent proteasomal degradation. On the contrary, PHF20L1 associates with SOX2 and protects SOX2 from degradation (Figs. 4 and 5 and Figure $\mathrm{S} 3$ ), which might through recognizing the methylated SOX2 by the MBT domain of PHF20L1 (Fig. 6).

Different from the canonical function of MLL1/WDR5 complexes on gene transcription regulation, we found that silencing of the MLL1/WDR5 complexes reduced the protein level of SOX2, but not mRNA level of SOX2 as well as PHF20L1. And the transcriptional activity of SOX2 is altered following its protein level changes (Fig. 7a, b and Figure S4). Therefore, we provided a novel mechanism for regulation of SOX2 stability by the MLL1/WDR5 and PHF20L1 (Fig. 7f).

Since SOX2 is considered as a driver for tumorigenesis and usually highly expressed in numerous cancers, we detected the expression of SOX2, WDR5, and PFH20L1 in ovarian teratoma tissues from clinical patients (Fig. 7c, Figure S5, Table S1, and Table S2). Our data showed positive correlation between SOX2 and PHF20L1 but negative correlation between SOX2 and WDR5. Soft agar colony formation assay and xenograft mouse model verified that ablation of PHF20L1 weakened the tumor initiation ability of PA-1 cells and loss of MLL1 could rescue the slowed growth of tumors induced by PHF20L1 knockdown (Fig. 7d, e). Further work is required to identify the ubiquitin E3 ligase that ubiquitinates SOX2 triggered by K42 methylation. Moreover, regulation of SOX2 by the MBT domain of PHF20L1 may provide a new perspective for designing new inhibitors for targeting the interaction between PHF20L1 and SOX2.

Acknowledgements Grant support from Natural Science Foundation of Guangdong Province (grant no. 2014A030313779), Innovation Program of Shenzhen (grant no. JCYJ20160527100529884 and JCYJ20170818085657917), Natural Science Foundation of SZU (grant no. 2017084), and National Institute of Health of USA (grant no. R15GM116087).

\section{Compliance with ethical standards}

Conflict of interest The authors declare that they have no conflict of interest.

\section{References}

1. Adameyko I, Lallemend F, Furlan A, et al. Sox 2 and Mitf crossregulatory interactions consolidate progenitor and melanocyte lineages in the cranial neural crest. Development. 2012;139:397-410.

2. Sarkar A, Hochedlinger K. The sox family of transcription factors: versatile regulators of stem and progenitor cell fate. Cell Stem Cell. 2013;12:15-30. 
3. Takahashi K, Yamanaka S. Induction of pluripotent stem cells from mouse embryonic and adult fibroblast cultures by defined factors. Cell. 2006;126:663-76.

4. Alonso MM, Diez-Valle R, Manterola L, et al. Genetic and epigenetic modifications of Sox 2 contribute to the invasive phenotype of malignant gliomas. PLoS ONE. 2011;6:e26740.

5. Annovazzi L, Mellai M, Caldera V, Valente G, Schiffer D. SOX2 expression and amplification in gliomas and glioma cell lines. Cancer Genomics Proteomics. 2011;8:139-47.

6. Bass AJ, Watanabe $\mathrm{H}$, Mermel $\mathrm{CH}$, et al. SOX2 is an amplified lineage-survival oncogene in lung and esophageal squamous cell carcinomas. Nat Genet. 2009;41:1238-42.

7. Freier K, Knoepfle K, Flechtenmacher C, et al. Recurrent copy number gain of transcription factor SOX2 and corresponding high protein expression in oral squamous cell carcinoma. Genes Chromosomes Cancer. 2010;49:9-16.

8. Hussenet T, Dali S, Exinger J, et al. SOX2 is an oncogene activated by recurrent $3 q 26.3$ amplifications in human lung squamous cell carcinomas. PLoS ONE. 2010;5:e8960.

9. Hussenet T, du Manoir S. SOX2 in squamous cell carcinoma: amplifying a pleiotropic oncogene along carcinogenesis. Cell Cycle. 2010;9:1480-6.

10. Maier S, Wilbertz T, Braun M, et al. SOX2 amplification is a common event in squamous cell carcinomas of different organ sites. Hum Pathol. 2011;42:1078-88.

11. Rudin CM, Durinck S, Stawiski EW, et al. Comprehensive genomic analysis identifies SOX2 as a frequently amplified gene in small-cell lung cancer. Nat Genet. 2012;44:1111-6.

12. Bareiss PM, Paczulla A, Wang $\mathrm{H}$, et al. SOX2 expression associates with stem cell state in human ovarian carcinoma. Cancer Res. 2013;73:5544-55.

13. Basu-Roy U, Seo E, Ramanathapuram L, et al. Sox 2 maintains self renewal of tumor-initiating cells in osteosarcomas. Oncogene. 2012;31:2270-82.

14. Chen S, Xu Y, Chen Y, et al. SOX2 gene regulates the transcriptional network of oncogenes and affects tumorigenesis of human lung cancer cells. PLoS ONE. 2012;7:e36326.

15. Gangemi RM, Griffero F, Marubbi D, et al. SOX2 silencing in glioblastoma tumor-initiating cells causes stop of proliferation and loss of tumorigenicity. Stem Cells. 2009;27:40-8.

16. Herreros-Villanueva M, Zhang JS, Koenig A, et al. SOX2 promotes dedifferentiation and imparts stem cell-like features to pancreatic cancer cells. Oncogenesis. 2013;2:e61.

17. Leis O, Eguiara A, Lopez-Arribillaga E, et al. Sox 2 expression in breast tumours and activation in breast cancer stem cells. Oncogene. 2012;31:1354-65.

18. Rybak AP, Tang D. SOX2 plays a critical role in EGFR-mediated self-renewal of human prostate cancer stem-like cells. Cell Signal. 2013;25:2734-42.

19. Singh S, Trevino J, Bora-Singhal N, et al. EGFR/Src/Akt signaling modulates Sox 2 expression and self-renewal of stem-like side-population cells in non-small cell lung cancer. Mol Cancer. 2012;11:73

20. Tian T, Zhang Y, Wang S, Zhou J, Xu S. Sox2 enhances the tumorigenicity and chemoresistance of cancer stem-like cells derived from gastric cancer. J Biomed Res. 2012;26: $336-45$.

21. Xu C, Xie D, Yu SC, et al. beta-Catenin/POU5F1/SOX2 transcription factor complex mediates IGF-I receptor signaling and predicts poor prognosis in lung adenocarcinoma. Cancer Res. 2013;73:3181-9.

22. Tomioka M, Nishimoto M, Miyagi S, et al. Identification of Sox-2 regulatory region which is under the control of Oct-3/4-Sox-2 complex. Nucleic Acids Res. 2002;30:3202-13.

23. Boyer LA, Lee TI, Cole MF, et al. Core transcriptional regulatory circuitry in human embryonic stem cells. Cell. 2005;122:947-56.
24. Loh YH, Wu Q, Chew JL, et al. The Oct4 and Nanog transcription network regulates pluripotency in mouse embryonic stem cells. Nat Genet. 2006;38:431-40.

25. Marques-Torrejon MA, Porlan E, Banito A, et al. Cyclindependent kinase inhibitor p21 controls adult neural stem cell expansion by regulating Sox 2 gene expression. Cell Stem Cell. 2013;12:88-100.

26. Julian LM, Vandenbosch R, Pakenham CA, et al. Opposing regulation of Sox 2 by cell-cycle effectors E2f3a and E2f $3 b$ in neural stem cells. Cell Stem Cell. 2013;12:440-52.

27. Fang L, Zhang L, Wei W, et al. A methylation-phosphorylation switch determines Sox 2 stability and function in ESC maintenance or differentiation. Mol Cell. 2014;55:537-51.

28. Qi D, Wang Q, Yu M, Lan R, Li S, Lu F. Mitotic phosphorylation of SOX2 mediated by Aurora kinase A is critical for the stem-cell like cell maintenance in PA-1 cells. Cell Cycle. 2016;15:2009-18.

29. Jeong CH, Cho YY, Kim MO, et al. Phosphorylation of Sox2 cooperates in reprogramming to pluripotent stem cells. Stem Cells. 2010;28:2141-50.

30. Mendelsohn BA, Pronold M, Long R, Smaoui N, Slavotinek AM. Advanced bone age in a girl with Wiedemann-Steiner syndrome and an exonic deletion in KMT2A (MLL). Am J Med Genet A. 2014;164A:2079-83.

31. Hsieh JJ, Ernst P, Erdjument-Bromage H, Tempst P, Korsmeyer SJ. Proteolytic cleavage of MLL generates a complex of N- and C-terminal fragments that confers protein stability and subnuclear localization. Mol Cell Biol. 2003;23:186-94.

32. Takeda S, Chen DY, Westergard TD, et al. Proteolysis of MLL family proteins is essential for taspase1-orchestrated cell cycle progression. Genes Dev. 2006;20:2397-409.

33. Dou Y, Milne TA, Ruthenburg AJ, et al. Regulation of MLL1 H3K4 methyltransferase activity by its core components. Nat Struct Mol Biol. 2006;13:713-9.

34. Wysocka J, Swigut T, Milne TA, et al. WDR5 associates with histone $\mathrm{H} 3$ methylated at $\mathrm{K} 4$ and is essential for $\mathrm{H} 3 \mathrm{~K} 4$ methylation and vertebrate development. Cell. 2005;121:859-72.

35. Jiang Y, Liu L, Shan W, Yang ZQ. An integrated genomic analysis of Tudor domain-containing proteins identifies PHD finger protein 20-like 1 (PHF20L1) as a candidate oncogene in breast cancer. Mol Oncol. 2016;10:292-302.

36. Esteve PO, Terragni J, Deepti K, et al. Methyllysine reader plant homeodomain (PHD) finger protein 20-like 1 (PHF20L1) antagonizes DNA (cytosine-5) methyltransferase 1 (DNMT1) proteasomal degradation. J Biol Chem. 2014;289:8277-87.

37. Yu ZK, Gervais JL, Zhang H. Human CUL-1 associates with the SKP1/SKP2 complex and regulatesp21(CIP1/WAF1) and cyclin D proteins. Proc Natl Acad Sci USA. 1998;95:11324-9.

38. Akagi T, Sasai K, Hanafusa H. Refractory nature of normal human diploid fibroblasts with respect to oncogene-mediated transformation. Proc Natl Acad Sci USA. 2003;100:13567-72.

39. Borowicz S, Van Scoyk M, Avasarala S, et al. The soft agar colony formation assay. J Vis Exp. 2014;92:e51998.

40. Zhang X, Lu F, Wang J, et al. Pluripotent stem cell protein Sox2 confers sensitivity to LSD1 inhibition in cancer cells. Cell Rep. 2013;5:445-57.

41. Nakamura T, Mori T, Tada S, et al. ALL-1 is a histone methyltransferase that assembles a supercomplex of proteins involved in transcriptional regulation. Mol Cell. 2002;10:1119-28.

42. Ruthenburg AJ, Wang W, Graybosch DM, et al. Histone H3 recognition and presentation by the WDR5 module of the MLL1 complex. Nat Struct Mol Biol. 2006;13:704-12.

43. James LI, Barsyte-Lovejoy D, Zhong N, et al. Discovery of a chemical probe for the L3MBTL3 methyllysine reader domain. Nat Chem Biol. 2013;9:184-91.

44. Justilien V, Walsh MP, Ali SA, Thompson EA, Murray NR, Fields AP. The PRKCI and SOX2 oncogenes are coamplified and 
cooperate to activate Hedgehog signaling in lung squamous cell carcinoma. Cancer Cell. 2014;25:139-51.
45. Girouard SD, Laga AC, Mihm MC, et al. SOX2 contributes to melanoma cell invasion. Lab Invest. 2012;92:362-70.

\section{Affiliations}

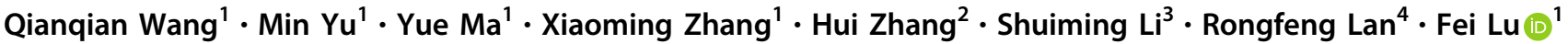

$1 \quad$ State Key Laboratory of Chemical Oncogenomics, Key Laboratory of Chemical Genomics, School of Chemical Biology \& Biotechnology, Peking University Shenzhen Graduate School, Shenzhen 518055, China

2 Department of Chemistry and Biochemistry, University of Nevada, Las Vegas, NV 89154, USA
3 Key Laboratory of Marine Bioresource \& Ecology, College of Life Science, Shenzhen University, Shenzhen 518060, China

4 Department of Cell Biology \& Medical Genetics, Shenzhen University Health Science Center, Shenzhen 518071, China 